\title{
Effectiveness of aronia berries for reduction of mild fibrosis and gene expression analysis in livers from mice fed a high-fat diet with aronia berries
}

\author{
Takuya Yamane ${ }^{1, *}$, Miyuki Kozuka ${ }^{2}$, Yoshio Yamamoto ${ }^{3}$, Yoshihisa Nakano ${ }^{4}$, \\ Takenori Nakagaki ${ }^{5}$, Iwao Ohkubo ${ }^{6}$, Hiroyoshi Ariga ${ }^{1}$
}

${ }^{1}$ Faculty of Pharmaceutical Sciences, Hokkaido University, Kita-ku, Sapporo 060-0812, Japan;

${ }^{2}$ Department of Health and Nutrition, Faculty of Human Science, Hokkaido Bunkyo University, Eniwa 061-1449, Japan; ${ }^{3}$ Laboratory of Environmental Chemistry, Mie University Iga Research Institute, Yumegaoka, Iga 518-0131, Japan; ${ }^{4}$ Center for Research and Development Bioresources, Research Organization for University-Community Collaborations, Osaka Prefecture University, Sakai, Osaka 599-8570, Japan; ${ }^{5}$ Institute of Food sciences, Nakagaki Consulting Engineer Co. Ltd., Nishi-ku, Sakai 593-8328, Japan; ${ }^{6}$ Department of Nutrition, School of Nursing and Nutrition, Tenshi College, Higashi-ku, Sapporo 065-0013, Japan

*Corresponding author: Takuya Yamane, PhD, Faculty of Pharmaceutical Sciences, Hokkaido University, Sapporo 060-0812, Japan

Submission date: January 28, 2016; Acceptance date: March 13, 2016: Publication date: March 16,2016

\begin{abstract}
:
Background: Aronia berries have many potential effects on health, including an antioxidant effect, effect for antimutagenesis, hepatoprotection and cardioprotection, an antidiabetic effect and inhibition of cancer cell proliferation. Previous human studies have shown that aronia juice may be useful for treatment of obesity disorders.
\end{abstract}

Objective: To reveal relationship between beneficial effect and the gene expression change by aronia berries, we analyzed mice livers using RNA sequencing and RT-qPCR.

Method: At 28 days after starting a normal diet, a high fat diet and a high-fat diet containing $10 \%$ freeze-dried aronia berries, serum was obtained from veins of mice after isoflurane 
anesthesia, and liver tissues were isolated and weighed. Triglyceride, total cholesterol and LDL cholesterol levels were measured and total RNAs were extracted. cDNA libraries were prepared according to Illumina protocols and sequenced using an Illumina HiSeq2500 to perform 100 paired-end sequencing. RNA-sequence reads mapping was performed using a DNA nexus. Gene expression analysis was performed. The liver tissue specimens were fixed and embedded in paraffin. After 5- $\mu$ m-thick paraffin sections had been cut, they were stained with hematoxylin-eosin using the standard procedure and also with Sirius Red.

Results: In this study, we found that mild fibrosis induced by a high-fat diet was reduced in livers of mice fed a high-fat diet containing aronia berries. RNA sequencing and RT-qPCR analyses revealed that gene expression levels of Igfbpl and Gadd45g were increased in livers from mice fed a high-fat diet containing aronia berries. Furthermore, results of an enzyme-linked immunoassay showed that a secreted protein levels of FABP1 and FABP4 were reduced in serum from mice fed a high-fat diet containing aronia berries. The results suggest that aronia berries have beneficial effects on mild fibrosis in liver.

Conclusion: Aronia berries have a beneficial effect on liver fibrosis. The recovery from liver fibrosis is associated with expression levels of Gadd45g and Igfbpl in the liver. The beneficial effects of aronia berries on liver fibrosis reduce the risk of liver cancer diseases and insulin resistance, resulting in reduction of serum FABP1 and FABP4 levels.

Keywords: aronia; fibrosis; liver; Igfbp1; Gadd45g

\section{INTRODUCTION:}

Aronia berries have been used in traditional medicine to treat atherosclerosis and hypertension in Russia and Eastern European countries [1]. Aronia berries have high contents of phenolic phytochemicals. The concentrations of active compounds in aronia berries, including anthocyanins, procyanidins and flavonoids, are over five-fold higher than those in cranberries [2, 3]. Aronia berries also have various potential health effects, including an antioxidant effect by radical scavenging activity, antimutagenesis by phenolic compounds, hepatoprotection by anthocyanins, which decrease the toxicity and accumulation of cadmium, cardioprotection in men with mild hypercholesterolaemia, antidiabetic effect, and inhibition of colon cancer cell proliferation [4]. Aronia juice has been shown to have beneficial effects on total cholesterol and 
lipid levels [5]. Furthermore, human studies have suggested that aronia juice is useful for treatment of obesity disorders [6]. Recently, we reported that cyanidin 3, 5-diglucoside is a new inhibitor present in aronia juice [7].

In this study, we found that the mild fibrosis of livers in mice that had been fed a high-fat diet containing aronia berries (Aronia group) was decreased and RNA sequencing and RT-qPCR analyses also revealed that expression levels of Gadd45g and Igfbpl genes in livers from mice in the Aronia group had recovered to control levels. These results suggest that aronia berries has beneficial effects on mild fibrosis of the liver.

\section{MATERIALS AND METHODS:}

Materials: Aronia berries were obtained from Hokusan (Kitahiroshima, Japan), and they were freeze-dried. RNAlater and RNeasy Mini were purchased from Qiagen (Venlo, Netherlands). PrimeScript RT Master Mix and high-fat diet D12492 were obtained from Takara (Seta, Shiga, Japan) and Research DietInc. (New Brunswick, NJ), respectively. All other chemicals were of analytical grade and were purchased from Wako Pure Chemicals (Osaka, Japan).

Animals: C57BL/6JmsSlc male mice were obtained at 4 weeks of age from Japan SLC (Tokyo, Japan). All mice were housed under an SPF condition and basically fed a normal diet (CRF-1, Oriental Yeast, Inc. Tokyo, Japan) for 2 weeks. Mice were divided into three groups, a group fed a normal diet (Control group), a group fed a high-fat diet (HFD group) and a group fed a high-fat diet containing $10 \%$ freeze-dried aronia berries (Aronia group). There were five mice in each group. At 28 days after starting the diets, serum was obtained from veins of mice after isoflurane anesthesia, and liver tissues were isolated and weighed.

Biochemical measurements: Triglyceride, total cholesterol and LDL cholesterol levels were measured using triglyceride assay, total cholesterol assay and LDL cholesterol assay kits, respectively (Wako, Osaka, Japan).

Hematoxylin-eosin and Sirius Red staining: The liver tissue specimens were fixed with $10 \%$ formalin in a neutral buffer and embedded in paraffin. After 5- $\mu$ m-thick paraffin sections had been cut, they were stained with hematoxylin-eosin using the standard procedure and also with Sirius Red. 
RNA isolation and library preparation for RNA sequence analysis: Total RNAs were extracted from tissues using an RNeasy Mini Kit. The quality and quantity of total RNA samples were assessed using a NanoDrop 1000 spectrophotometer (Thermo Scientific, Wilmington) and 2100 Bioanalyzer (Agilent Technologies, Tokyo, Japan). cDNA libraries were prepared according to Illumina protocols and sequenced using an Illumina HiSeq2500 to perform 100 paired-end sequencing. RNA-sequence reads mapping was performed using a DNA nexus. Gene expression analysis was performed using Gene spring software (Agilent Technologies, Tokyo, Japan).

Reverse transcription-quantitative polymerase chain reaction: Total RNAs were prepared from livers from mice using an RNeasy mini kit. Reverse transcription was carried out in a mixture containing $500 \mathrm{ng}$ of total RNAs and specific primers under the conditions of $95^{\circ} \mathrm{C}$ for $30 \mathrm{sec}, 40$ cycles of $95^{\circ} \mathrm{C}$ for $10 \mathrm{sec}$, and $60^{\circ} \mathrm{C}$ for $30 \mathrm{sec}$ by using an SYBR Premix Ex Taq II (Takara) and a real-time PCR system (MiniOpticon, Bio-Rad, Hercules, CA). $\beta$-actin (ACTB) mRNA was also amplified as an internal control. Nucleotide sequences of oligonucleotides used for primers of real-time PCR are shown Table 1.

Table 1. Nucleotide sequences of primers and PCR conditions used for RT-qPCR

\begin{tabular}{|c|c|c|c|}
\hline \multirow{2}{*}{$\begin{array}{l}\text { Gene } \\
\mathrm{mSaa} 2\end{array}$} & \multicolumn{2}{|c|}{ Nucleotide sequence } & \multirow{3}{*}{$\begin{array}{l}\text { PCR condition } \\
95^{\circ} \mathrm{C} 30 \mathrm{sec}, 95^{\circ} \mathrm{C} 10 \mathrm{sec}, \\
60^{\circ} \mathrm{C} 30 \mathrm{sec} \times 40 \text { cycles }\end{array}$} \\
\hline & sense & 5'-AGACACCAGCAGGATGAAGC-3' & \\
\hline & anti-sense & 5'-GTCTCCAGCCCCTTGGAAAG-3' & \\
\hline \multirow[t]{2}{*}{ mGadd $45 \mathrm{~g}$} & sense & 5'-GAGCTGGACTTAGCCGACTG-3' & $95^{\circ} \mathrm{C} 30 \mathrm{sec}, 95^{\circ} \mathrm{C} 10 \mathrm{sec}$, \\
\hline & anti-sense & 5'-AAGCTTCCACGATAGCGTCC-3' & $60^{\circ} \mathrm{C} 30 \mathrm{sec} \times 40$ cycles \\
\hline \multirow[t]{3}{*}{ mIgfbp 1} & sense & 5'-GCACCTTGTTCAGCTCCCAG-3' & $95^{\circ} \mathrm{C} 30 \mathrm{sec}, 95^{\circ} \mathrm{C} 10 \mathrm{sec}$, \\
\hline & onti conco & E, СтСтC & $60^{\circ} \mathrm{C} 30 \mathrm{sec} \times 40$ cycles \\
\hline & anti-sense & 5-СТСТСAGAAAGCTCATCCGC-3 & \\
\hline \multirow[t]{2}{*}{ mArl4d } & sense & 5'-CTACCTGCTAGGGGGTCAGT-3' & $95^{\circ} \mathrm{C} 30 \mathrm{sec}, 95^{\circ} \mathrm{C} 10 \mathrm{sec}$, \\
\hline & anti-sense & 5'-CTCCTTCAGTCCTTTGCGGT-3' & $60^{\circ} \mathrm{C} 30 \mathrm{sec} \times 40$ cycles \\
\hline mSerpina-4-p & sense & 5'-GAATGTGACTGGGGAGTGCT-3' & $95^{\circ} \mathrm{C} 30 \mathrm{sec}, 95^{\circ} \mathrm{C} 10 \mathrm{sec}$, \\
\hline s-1 & anti-sense & 5'-CCCCATGCCCTCCTGTATTG-3' & $60^{\circ} \mathrm{C} 30 \mathrm{sec} \times 40$ cycles \\
\hline \multirow[t]{2}{*}{ mArrdc3 } & sense & 5'-CGGCTCCAATACTGCCTATACA-3' & $95^{\circ} \mathrm{C} 30 \mathrm{sec}, 95^{\circ} \mathrm{C} 10 \mathrm{sec}$, \\
\hline & anti-sense & 5'-TGTGGAAGCCTTCTTCAGAATTA-3' & $60^{\circ} \mathrm{C} 30 \mathrm{sec} \times 40$ cycles \\
\hline \multirow[t]{2}{*}{ mACTB } & sense & 5'-CCCTAAGGCCAACCGTGAAA -3' & $95^{\circ} \mathrm{C} 30 \mathrm{sec}, 95^{\circ} \mathrm{C} 10 \mathrm{sec}$, \\
\hline & anti-sense & 5'-ACGACCAGAGGCATACAGGGA -3' & $60^{\circ} \mathrm{C} 30 \mathrm{sec} \times 40$ cycles \\
\hline
\end{tabular}


Enzyme-linked immunoassay: Serum levels of FABP1 and FABP4 were measured using mouse FABP1 and FABP4 ELISA kits (CycLex, Nagoya, Japan) according to the manufacturer's instruction manual.

Statistical analysis: Data are expressed as means \pm S.E. Statistical analyses were performed using analysis of variance (one-way ANOVA) followed by unpaired Student's $t$-test. For comparison of multiple samples, the Tukey-Kramer test was used.

Ethics statement: All animal experiments were carried out in accordance with the National Institutes of Health Guide for the Care and Use of Laboratory Animals, and the protocols were approved by the Committee for Animal Research at Safety Research Institute for Chemical Compounds (permit number: NP013-51-5) and Hokkaido University (permit number: 15-0009).

\section{RESULTS:}

Beneficial effects of aronia berries on serum and liver levels of LDL cholesterol and triglycerides: To examine the effects of aronia berries on levels of LDL cholesterol and triglycerides, high-fat diets with $10 \%$ freeze-dried aronia berries and without aronia berries were administered orally to mice in the Aronia group and high-fat diet (HFD) group, respectively. Twenty-eight days after the start of administration, livers were extracted from mice and their weights were measured. Serum was then extracted and levels of total cholesterol, LDL-cholesterol and triglycerides were measured. As shown in Fig. 1A, liver weight was not significantly changed in the three groups, and the increased total lipid level in mice in the HFD group was decreased to the level in control mice after administration of aronia berries (Aronia group). The levels of total cholesterol and triglycerides and the level of LDL cholesterol in the Aronia group were increased and decreased, respectively, compared to those in the control group, and these levels recovered to those in the control group (Fig. 1B). Although the total cholesterol level in serum of the HFD group was not significantly changed compared to that in the control group, the level of LDL cholesterol in serum of the HFD group was increased and also recovered to that in the control group (Fig.1C). 
A

Fig.1
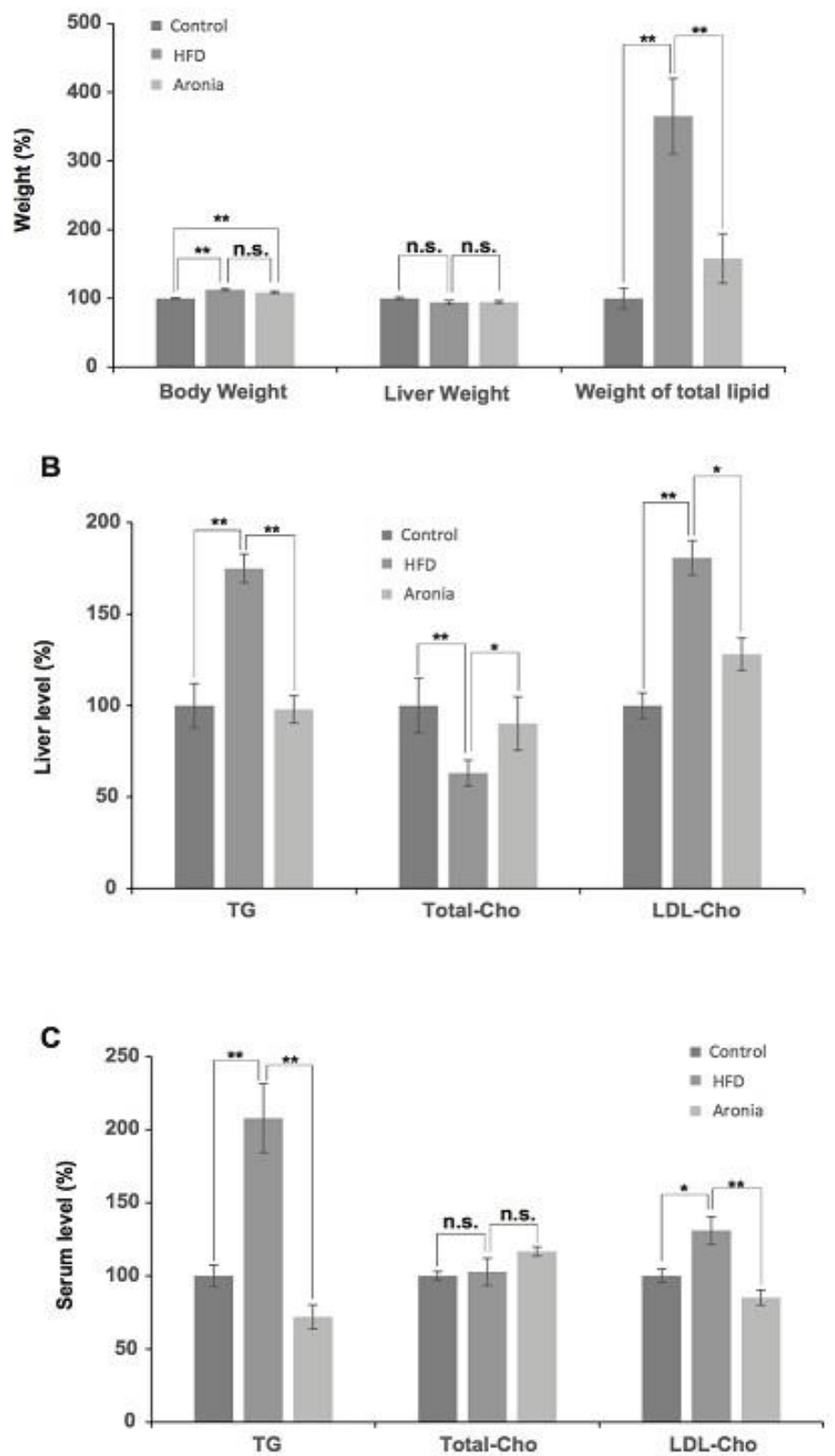

Figure 1. Reductions of total liver lipid and levels of LDL cholesterol and triglycerides in the liver and serum from mice fed a high-fat diet with aronia berries.

Beneficial effects of aronia berries on liver fibrosis: To examine the effect of aronia berries on liver fibrosis, livers from mice were embedded in paraffin and then paraffin sections were stained with hematoxylin-eosin and Sirius Red. As shown in Fig. 2D, mild fibrosis was observed in livers from mice fed a high-fat diet, and this phenomena was reduced after administration of aronia berries to mice in the HFD group (Fig. 2F). 


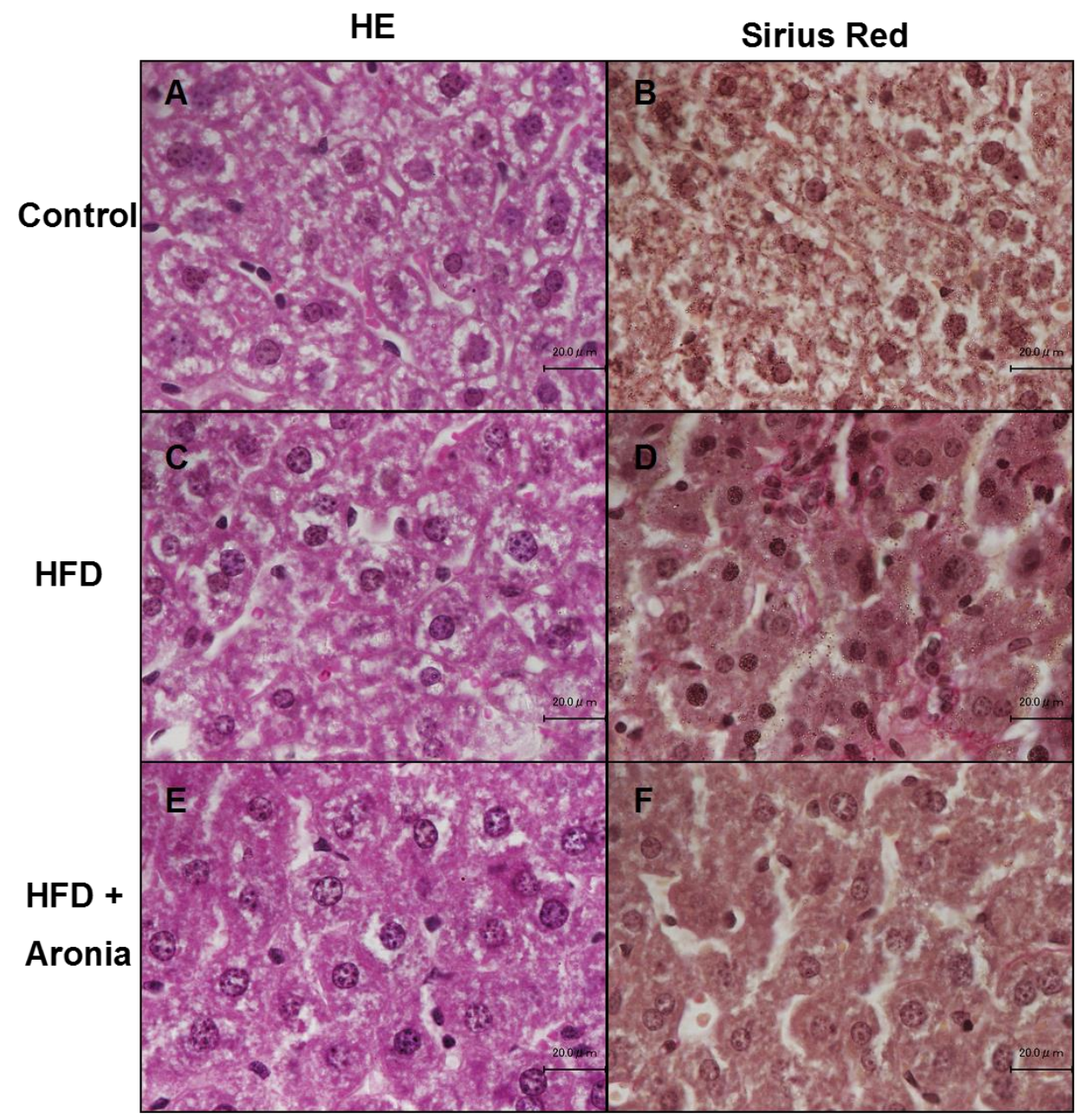

Figure 2. Effect of aronia berries on liver histology. A, B. Liver sections stained with hematoxylin-eosin (A) and Sirius Red (B) showed normal histology in mice fed a normal diet. C, D. Liver sections from mice fed a high-fat diet showed steatosis (C) and mild fibrosis (D). E, F. Liver sections from mice fed a high-fat diet containing freeze-dried aronia berries showed marked reduction of steatosis (E) and fibrosis (F). Magnification x100.

Gene expression analysis: To examine changes in expression levels of genes in mice fed high-fat diets with and without aronia berries, RNA sequence analysis was carried out using RNA extracted from livers of mice and an Illumina High-seq 2500 sequencer. Genes in mice in the Aronia group that showed a more than 2-fold change in expression levels compared to those in the control group are shown in Table 2. Up-regulated genes were Saa2, Gadd45g, Igfbp1, Arl4d, Cyp3a11, Mt2, Agxt2l1, Cyp4a12b, Slc25a25, 2310076L09Rik, Slc39a4 and Eaf2 and down-regulated genes were Serpina4-ps1, Arrdc3, Phlda1, Me1, Foxa2, Idi1 and Csad. 
High-fat diet and high-fat diet containing 10\% freeze-dried aronia berries were administered orally to mice in the HFD and Aronia groups, respectively. After 28 days, tissues and serum were obtained and used for biochemical analyses. A. Body weight, liver weight and total lipid, B. levels of triglycerides, total cholesterol and LDL-cholesterol in the liver, C. serum levels of triglycerides, total cholesterol and LDL-cholesterol. ${ }^{*} p<0.05, * * p<0.01$, n.s.: not significant.n=5.

Expression levels of four up-regulated and two down-regulated genes in mouse livers: Of genes in aronia berry-administered mice for which expression levels were changed by more than 3 fold compared to those in mice fed a high-fat diet, Saa2, Gadd45g, Igfbp1, Arl4d, Serpina4-ps1 and Arrdc3 genes were identified by RNA sequence analysis (Table 2). For validation, mRNA expression levels of these genes were analyzed by real-time PCR. As shown in Fig. 3, Gadd45g and Igfbpl mRNA levels in the Aronia group were recovered to levels in the control group. Saa2, Arl4d, Serpina4-ps1 and Arrdc3 mRNA levels in the Aronia group were not recovered to levels in the control group.

Table 2. Genes with changed expression levels in livers of mice fed a high-fat diet containing aronia berries. A. Genes in a subject group with increased expression in livers from mice that had been fed with high-fat diet containing aronia berries with an absolute fold change $\geq 2.0$

\begin{tabular}{llll}
\hline Gene symbol & Gene name & Accession number & Ratio \\
\hline Saa2 & Serum amyloid A2 & NM_011314 & 3.942 \\
Gadd45g & Growth arrest and DNA-damage-inducible 45 gamma & NM_011817 & 3.351 \\
Igfbp1 & Insulin-like growth factor binding protein 1 & NM_008341 & 3.042 \\
\hline Ar14d & ADP-ribosylation factor-like 4D & NM_025404 & 3.028 \\
Cyp3a11 & Cytochrome P450, family 3, subfamily a, polypeptide 11 & NM_007818 & 2.889 \\
Mt2 & Metallothionein 2 & NM_008630 & 2.702 \\
Agxt211 & Alanine-glyoxylate aminotransferase 2-like 1 & NM_027907 & 2.645 \\
Cyp4a12b & Cytochrome P450, family 4, subfamily a, polypeptide 12B & NM_172306 & 2.171 \\
Slc25a25 & Solute carrier family 25 member 25 & NM_146118 & 2.130 \\
2310076L09Rik & None & None & 2.125 \\
Slc39a4 & Solute carrier family 39 member 4 & NM_028064 & 2.082 \\
Eaf2 & ELL associated factor 2 & NM_001113401 & 2.048 \\
Spata2L & RIKEN full-length enriched library, clone:A830015E22 & AK139339 & 2.000 \\
\hline
\end{tabular}


B. Genes in a subject group with decreased expression of genes in livers from mice that had been fed with high-fat diet containing aronia extract with an absolute fold change $\geq 2.0$

\begin{tabular}{llll}
\hline Gene symbol & Gene name & $\begin{array}{l}\text { Accession } \\
\text { number }\end{array}$ & Ratio \\
\hline Serpina4-ps1 & Serine (or cysteine) peptidase inhibitor, clade & BC031891 & 0.149 \\
& A, member 4, pseudogene 1 & & \\
Arrdc3 & arrestin domain containing 3 & NM_001042591 & 0.260 \\
Phlda1 & Pleckstrin homology-like domain, family A, & NM_009344 & 0.360 \\
& member 1 & & \\
Me1 & Malic enzyme 1, NADP(+)-dependent, & NM_001198933 & 0.421 \\
& cytosolic & & \\
Foxa2 & Forkhead box A2 & NM_010446 & 0.432 \\
Idi1 & Isopentenyl-diphosphate delta isomerase & NM_145360 & 0.451 \\
Csad & Cysteine sulfinic acid decarboxylase & NM_144942 & 0.460 \\
\hline
\end{tabular}

Fig.3

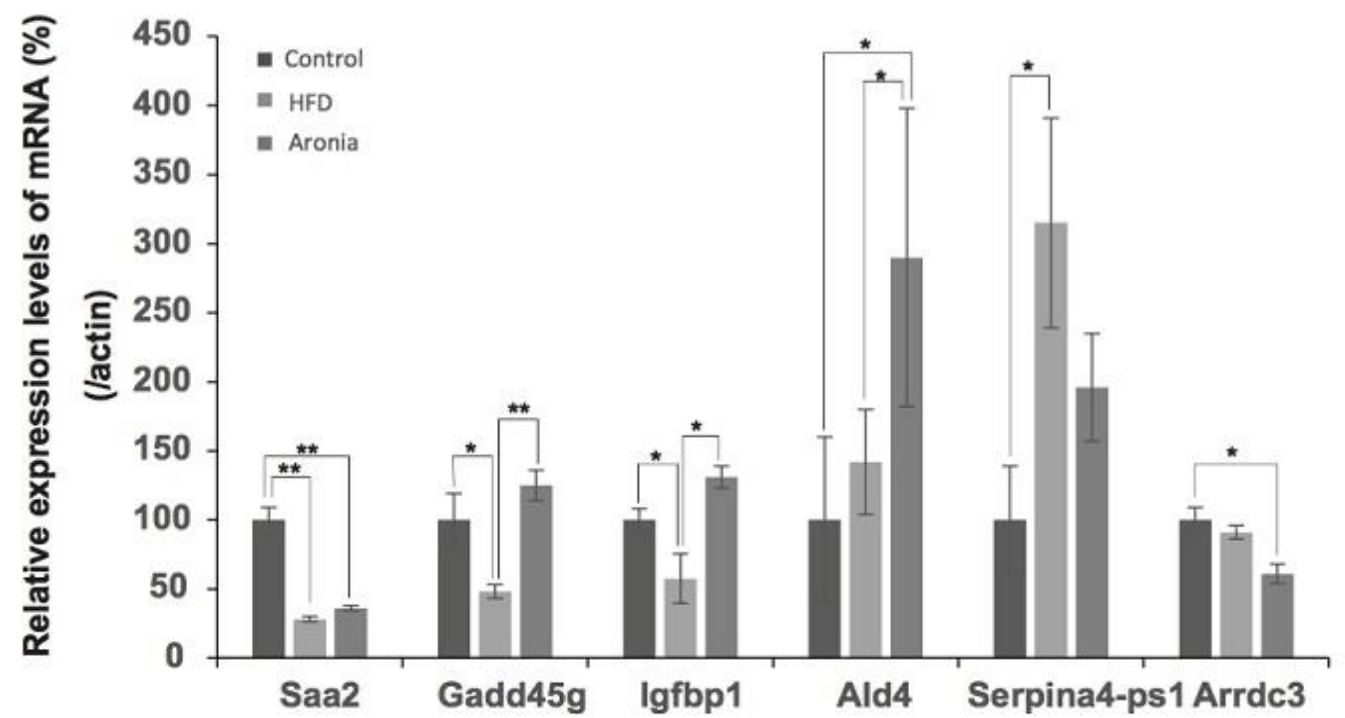

Figure 3. Validation by real-time PCR of up-regulated and down-regulated gene expression in livers from mice fed aronia berries ${ }^{*} p<0.05,{ }^{* *} p<0.01, \mathrm{n}=5$. 
Expression levels of FABP1 and FABP4 in serum: To examine expression levels of FABP1 and FABP4 in serum of mice, enzyme-linked immunoassays using specific antibodies were carried out. As shown in Fig. 4, the levels of FABP1 and FABP4 in the Aronia group were decreased by $29 \%$ and $66 \%$ of those in the control group, respectively.
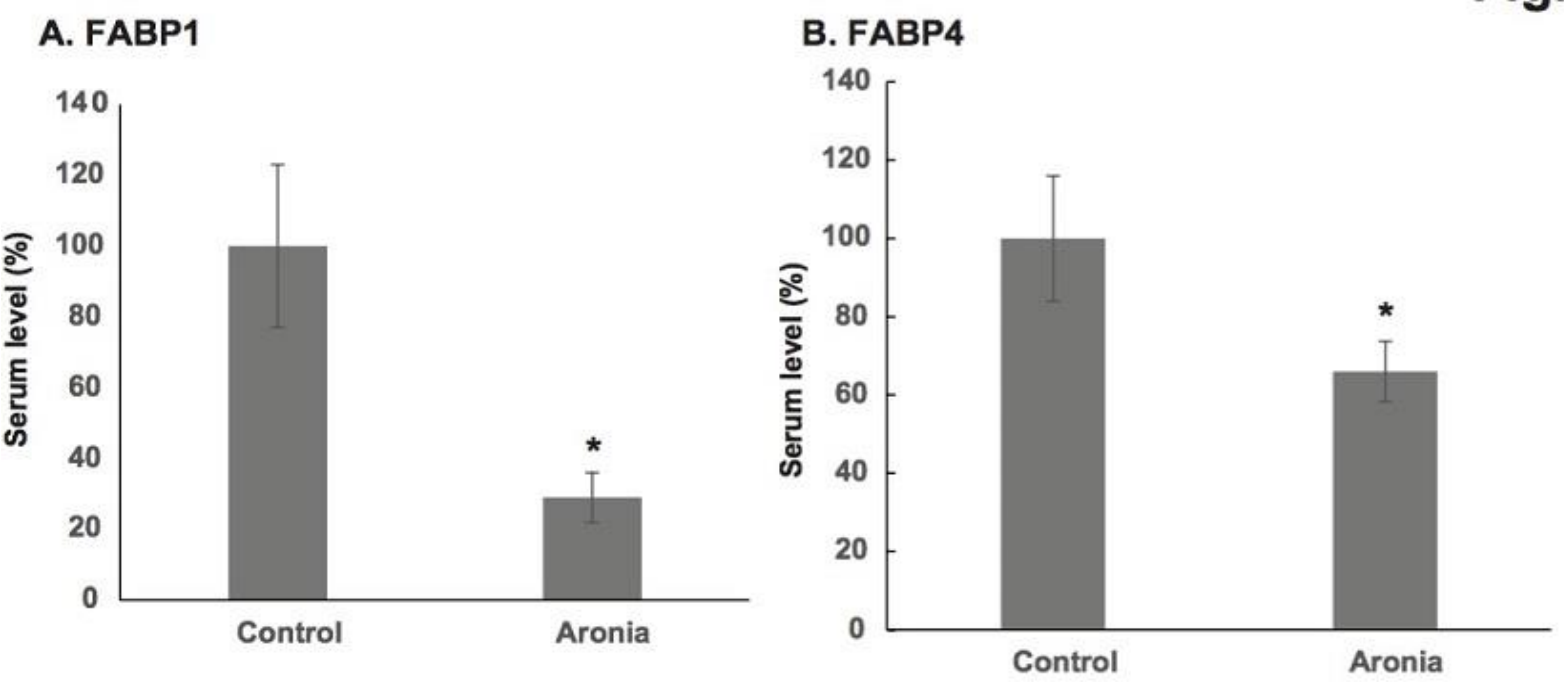

Figure 4. Changes in serum levels of FABP1 and FABP4 in mice fed aronia berries.

Serum levels of FABP1 (A) and FABP4 (B) in the HFD and Aronia groups were measured by ELISA. $*_{p}<0.05, \mathrm{n}=5$.

\section{DISCUSSION:}

A previous human study showed that aronia juice may be useful for treatment for obesity disorders [6]. However, the mechanisms underlying its effect are not fully understood. In this study, we found that the weight of total lipid in the liver and levels of LDL cholesterol and triglycerides in the liver and serum from mice that had been fed a high-fat diet recovered to control levels after administration of aronia berries to mice. The results of recovery of LDL cholesterol and triglyceride levels in the liver and serum to control levels in the Aronia group are consistent with results of previous human studies [5, 6]. Gene expression analysis revealed twelve up-regulated and seven down-regulated genes for which expression levels in the Aronia group were more than 2-fold higher and lower than those in the HFD group. Furthermore, we found that decreased mRNA expression levels of Gadd45g and Igfbpl in livers were recovered in the Aronia group. Gadd45g is a stress response gene against stress signals such as signals toward inflammatory and pro-apototic cytokines, mitogenic stimuli and xenobiotics [8]. 
Downregulation of the Gadd45g gene is mediated mainly by promoter methylation [9-11]. Functions of GADD45G are tumor suppression [11,12] and inhibition of cell proliferation though cell cycle arrest at the G1/S or G2/M phase [13]. IGFBP1 inhibits insulin-like growth factor (IGF)-stimulated proliferation and stimulates differentiation of preadipocytes into mature adipocytes, and it inhibits glucose uptake and IGF-inhibited lipolysis in mature adipocytes [14]. IGFBP1 levels are also decreased in obese postmenopausal women with hyperinsulinemia and are correlated with insulin sensitivity. A low serum IGFBP1 level is known to be associated with a number of cardiovascular risk factors [15]. These previous findings and findings in this study suggest that aronia berries include a compound(s) that regulates the gene expression of Gadd45g and Igfbpl and that levels of liver fibrosis, liver total lipid, triglycerides and LDL-cholesterol were recovered to control levels through functions of these genes. Gene expression of Gadd45g is regulated by Oct and NF-Y elements [16]. Gene expression of IGFBPI is regulated by insulin-responsive element (IRE) [17] and that of Igfbpl is regulated by glucocorticoid-responsive element (GRE) [18]. A functional compound(s) in aronia berries may bind to these elements binding proteins and regulate gene expression of Gadd45g and Igfbpl. Furthermore, we found that serum levels of FABP1 and FABP4 were reduced in the Aronia group. The serum level of FABP1 has been reported to be a biomarker for fatty liver disease [19], and the serum level of FABP4 is positively correlated with markers of metabolic syndrome and vascular diseases [20]. These results suggest that the beneficial effect of aronia berries on liver fibrosis is elicited by a compound(s), resulting in reduction of serum FABP1 and FABP4 levels. Thus, the model of recovery from liver fibrosis by these genes is as follows: The expression levels of Igfbpl and Gadd45g mRNAs are increased, and then increased IGFBP1 accelerates the inhibition of proliferation and stimulates differentiation of preadipocytes to mature adipocytes and promotes lipolysis. Increased Gadd45g also accelerates the inhibition of proliferation and suppresses liver inflammation and tumor growth, resulting in reduction of liver fibrosis.

\section{CONCLUSION:}

Aronia berries have a beneficial effect on liver fibrosis. The recovery from liver fibrosis is associated with expression levels of Gadd45g and Igfbpl in the liver. The beneficial effects of aronia berries on liver fibrosis reduce the risk of liver cancer diseases and insulin resistance, resulting in reduction of serum FABP1 and FABP4 levels. Further study is needed to identify the compound(s) in aronia berries that is effective against liver fibrosis through regulation of Gadd45g and Igfbp1 expression. 
Abbreviations: IGFBP1, insulin-like growth factor-binding protein 1; GADD45G, growth arrest and DNA damage 45G; FABP1, fatty acid-binding protein 1; FABP4, fatty acid-binding protein 4.

Competing Interests: The authors have declared that no competing interests exist.

Acknowledgements: We thank Ryo Yokotani (Safety Research Institute for Chemical Compounds Co., Ltd.) for technical assistance in animal experiments.

\section{REFERENCES:}

1. Kokotkiewicz A, Jaremicz Z, Luczkiewicz M: Aronia plants: a review of traditional use, biological activities, and perspectives for modern medicine. J Med Food 2010, 13: 255-269.

2. $\mathrm{Wu} \mathrm{X}, \mathrm{Gu} \mathrm{L}$, Prior RL, McKay S: Characterization of anthocyanins and proanthocyanidins in some cultivars of Ribes, Aronia, and Sambucus and their antioxidant capacity. J Agric Food Chem 2004, 52: 7846-7856.

3. Wu X, Beecher GR, Holden JM, Haytowitz DB, Gebhardt SE, Prior RL: Concentrations of anthocyanins in common foods in the United States and estimation of normal consumption. J Agric Food Chem 2006, 54: 4069-4075.

4. Kulling ES, Rawel MH: Chokeberry (Aronia melanocarpa) -A Review on the Characteristic Components and Potential Health Effects, Planta Med 2008, 74: 1625-1634.

5. Simeonov SB, Botushanov NP, Karahanian EB, Pavlova MB, Husianitis HK, Troev DM: Effects of Aronia melanocarpa juice as part of the dietary regimen in patients with diabetes mellitus. Folia Med (Plovdiv) 2002, 44: 20-23.

6. Zielinska-Przyjemska M, Olejnik A, Dobrowolska-Zachwieja A, Grajek W: Effects of Aronia melancarpa polyphenols on oxidative metabolism and apoptosis of neutrophils from obese and non-obese individuals. Acta Sci Pol Technol Aliment 2007, 6: 75-87.

7. Kozuka M, Yamane T, Nakano Y, Nakagaki T, Ohkubo I, Ariga H: Identification and characterization of a dipeptidyl peptidase IV inhibitor from aronia juice. Biochem Biophys Res Commun 2015, 465: 433-436.

8. Moskalev AA, Smit-McBride Z, Shaposhnikov MV, Plyusnina EN, Zhavoronkov A, Budovsky A, Tacutu R, Fraifeld VE: Gadd45 proteins: relevance to aging, longevity and age-related pathologies. Ageing Res Rev 2012, 11: 51-66. 
9. Guo W, Dong Z, Guo Y, Chen Z, Kuang G, Yang Z: Methylation mediated repression of GADD45A and GADD45G expression in gastric cardia adenocarcinoma. Int $\mathrm{J}$ Cancer 2013, 133: 2043-2053.

10. Guo W, Zhu T, Dong Z, Cui L, Zhang M, Kuang G: Decreased expression and aberrant methylation of Gadd45G is associated with tumor progression and poor prognosis in esophageal squamous cell carcinoma. Clin. Exp. Metastasis 2013, 30: 977-992.

11. Tamura RE, de Vasconcellos JF, Sarkar D, Libermann TA, Fisher PB, Zerbini LF: GADD45 proteins: central players in tumorigenesis. Curr Mol Med 2012, 12: 634-651.

12. Liebermann DA, Tront JS, Sha X, Mukherjee K: Mohamed-Hadley A, B. Hoffman, Gadd45 stress sensors in malignancy and leukemia. Crit. Rev. Oncog. 2011, 16: 129-140.

13. Fan W, Richter G, Cereseto A, Beadling C, Smith KA: Cytokine response gene 6 induces p21 and regulates both cell growth and arrest. Oncogen 1999, e 18: 6573-6582.

14. Siddals WK, Westwood M, Gibson MJ, White A: IGF-binding protein-1 inhibits IGF effects on adipocyte function: implications for insulin-like actions at the adipocyte. $\mathrm{J}$ Endocrinol 2002, 174: 289-297.

15. Ruan W, Lai M: Insulin-like growth factor binding protein: a possible marker for the metabolic syndrome? Acta Diabetol 2010, 47: 5-14.

16. Campanero MR, Herrero A, Calvo V: The histone deacetylase inhibitor trichostatin A induces GADD45c expression via Oct and NF-Y binding sites. Oncogene 2008, 27: $1263-1272$.

17. Suwanickul A, Morris SL, Powell DR: Identification of an insulin-responsive element in the promoter of the human gene for insulin-like growth factor binding protein-1. J Biol Chem 1993, 268: 17063-17068.

18. Suh DS, Ooi GT, Rechler MM: Identification of cis-elements mediating the stimulation of rat insulin-like growth factor-binding protein-1 promoter activity by dexamethasone, cyclic adenosine 3',5'-monophosphate, and phorbol esters, and inhibition by insulin. Mol Endocrinol 1994, 8: 794-805.

19. Chen A, Tang Y, Davis V, Hsu FF, Kennedy MS, Song H, Turk J, Brunt ME, Newberry PE, Davidson ON: Liver fatty acid binding protein (L-Fabp) modulates murine stellate cell activation and diet-induced nonalcoholic fatty liver disease. HEPATOLOGY 2013, 57: 2202-2012.

20. Kralisch S, Fasshauer M: Adipocyte fatty acid binding protein: a novel adipokine involved in the pathogenesis of metabolic and vasculardisease? Diabetologia 2013, 56: 10-21. 